Barbosa, Regina.

Profesor en la Univesidad Anhembi Morumbi - Brasil.

\title{
Una Bomba Arrojada: reflexiones sobre razones y efectos de yarnbombing.
}

\section{A Bomb Was Launched: reflections on reasons and effects of yarnbombing.}

TIPO DE TRABAJO:

Comunicación virtual

PALABRAS CLAVE:

Yarnbombing, craftivismo, espacio urbano, trabajos hechos con agujas.

KEY WORDS:

Yarnbombing, craftivism, urban space, needlework.

RESUMEN

En este artículo se presenta la práctica de yarnbombing como una posición y una responsabilidad de las personas a partir del lugar en el cual viven. Estas intervenciones urbanas se producen mediante la re-territorialización de los actos anónimos y domésticos de trabajos hechos con agujas que se extienden sobre el espacio público, donde los grupos construyen discursos y posibles diálogos con los individuos de una manera divertida y próxima a través del craftivismo, forma de activismo que utiliza esas herramientas, materiales y técnicas tan familiares. Se pregunta si, por lo tanto, cuando explota una bomba de hilos si llega a impactar el entrelazamiento entre el mensaje de quien arroja la bomba, la lectura de aquel que es afectado por ella y los efectos sobre el paisaje.

ABSTRACT .

The following article presents the practice of yarnbombing as an action of taking position and responsibility of the practitioner(s) over the space where one lives in. Those interventions happen considering the re-territorialization of the anonymous and domestic acts of needlework that extend themselves over the public spaces, in which groups build discourses and possibilities of dialogue with the public, in a both playful and palpable way, through familiar tools, techniques and materials. It is questioned if, when it blows up, a bomb made of yarn brings with it as an impact the tangling between the message that the bombers want to send, what is read by those who were hit by it and the effects on the landscape.

CONTENIDO.

Introducción.

Una bomba fue arrojada. Un lugar fue sacudido, modificado. Los efectos causaron desvíos, marcó el paisaje. Las personas se vieron afectadas. La gente que transitaba allí, el lugar del lanzamiento de la bomba. Las personas que vivían en ese barrio, que apenas estaban de paso. Un grupo se atribuyó la responsabilidad. 


\author{
Barbosa, Regina \\ Una Bomba Arrojada: reflexiones sobre razones y efectos de yarnbombing \\ III CONGRESO INTERNACIONAL DE INVESTIGACIÓN EN ARTES VISUALES :: ANIAV $2017::$ GLOCAL [codificar, mediar, transformar, vivir] \\ http://dx.doi.org/10.4995/ANIAV.2017.4904
}

La bomba era coloreada, hecha con hilos de acrílico en colores vibrantes y resistentes a la intemperie. Llevaba postes de una plaza de recién inaugurada, cambiando, aunque sea temporalmente, el árido paisaje construido en hormigón y acero, incitando en las personas que circulan por allí todos los días, el deseo de parar, y por lo menos mirar de nuevo. La bomba era de tricot, ganchillo. Los transeúntes que por allí pasaban se sorprendieron, pero también reconocieron la bomba. Se asombraron de que esas cosas, tan cotidianas, habituales, comunes, estaban ahora en el espacio urbano, fuera de sus hogares, en la plaza.

El grupo que asume la responsabilidad del ataque, protesta, reclama para sí mismo el espacio de la calle que es también suya. Tan suya que es ahora un poco la casa de todos - del grupo y de quien está de paso.

A ese desbordamiento, de significados y territorios, se llama yarnbombing.

El yarnbombing, también conocido yarn storming, knit graffiti e guerrilla knitting es una especie de craftivismo, forma de activismo en la que el practicante se fusiona sus habilidades e intereses políticos "para luchar por un mundo mejor, a menudo tejiendo declaraciones políticas como forma de protesta "(Mann, 2015, p. 66), que tiene sus primeras acciones documentados a principios del siglo XXI.

\title{
Del cuarto de costura a la calle: repensando el club del tejido.
}

Se sabe que antes de que existiera la historia, indicado por sus eruditos con los orígenes de la invención de la escritura, ya había una producción de textiles y, a través de la construcción de hilos y las intervenciones sobre ellos, narrativas dibujaron-, se promovía la perpetuación de las técnicas y de la historia del grupo. Se construía sin palabras, un texto táctil y visual, cuya producción se perpetúa en la intimidad, aunque aprendido y diseminada en un contexto colectivo. Un ejemplo de esta construcción de la narrativa es el tapiz de Bayeux, que data de alrededor de 1080. Este tapiz es una pieza de lino que mide más de 70 metros donde están "glorificadas" en bordado, los hechos de Guillermo II de Normandía en la batalla de Hastings. Su autoría se atribuye a la reina Matilde, la esposa de William, conocida como bordadora ejemplar, y habría trabajado con otras mujeres en reclusión con el fin de inmortalizar los logros de su marido, sin esperar reconocimiento, aunque haciendo el trabajo tan minucioso. (Parker, 1989)

En otras partes del mundo, se produjeron escenas de menos relieve. Este es el caso de las producciones que se encuentran en Ninhue e Isla Negra (Gostelow, 1983) en Chile, donde se retratan escenas cotidianas en construcciones que utilizan al mismo tiempo el bordado y patchwork, llamado needlepainting.

Sin embargo, la mayor parte de lo que se produce en estas actividades anónimas y domésticas tiene como función básica la construcción de narrativas. El producto del trabajo de la aguja tiene la utilidad de vestir cuerpos y casas. Por lo que incluso el ciudadano más alejado de la sociedad reconoce la vida doméstica de una toallita de ganchillo, sin duda en algún momento vistió una malla hecha a mano y vio o tiene un paño de cocina con borde bordado en punto de cruz. De esa manera, el retrato de la vida cotidiana, o las labores de alguien son desvíos con respecto a la proposición inicial de esos objetos.

El ejercicio de la construcción textil, como se dijo anteriormente, era aprendido en grupo hasta las últimas tres décadas del siglo XX, de acuerdo con Rozsika Parker (2010), los trabajos de agujas son rechazados, pues se entienden en la Segunda ola feminista ${ }^{1}$ como las labores femeninas que servían como un instrumento de opresión, a pesar de ser una importante fuente de satisfacción creativa.

Sin embargo, en muchas situaciones, estos mismos trabajos de agujas, ofrece a las mujeres no sólo la ya mencionada "satisfacción creativa", pero la posibilidad de mostrar su descontento con situaciones contra las que se rebelan. El uso de las técnicas empleadas en Ninhue e Isla Negra, la arpilleras también producidas tradicionalmente en Chile, llegó a ser conocido internacionalmente cuando, durante la dictadura de Pinochet (1973-1990) subvirtieron el significado de lo que se entiende por cuotidiano para una población privada del derecho a hablar libremente (Agosin, 1987). En esos pedazos de tela, las mujeres cuyos esposos, padres, hijos, amigos fueron detenidos, torturados, asesinados o están desaparecidos, y a quien no pueden reclamar la libertad o el reembolso, denuncian los diversos aspectos de la vida bajo la dictadura, la angustia de no tener como para alimentar a los hijos, a los asesinatos y torturas ${ }^{2}$ (Ilustración 1).

\footnotetext{
${ }^{1}$ Entre los años 1960 y 1980, la llamada segunda ola del feminismo se entiende como una continuación de la primera ola del feminismo, que se produjo en las primeras décadas del siglo XX, en el sentido de que tanto en uno como en las otras mujeres se organizan en la demanda de sus derechos. Sin embargo, la primera ola del feminismo se basa en la demanda de derechos políticos - el derecho de sufragio de las mujeres - y la segunda onda tiene el lema final de la discriminación y la plena igualdad entre los sexos. Para una visión amplia sobre el tema, se indica el documental "She's Beautiful When She's Angry", disponible en su totalidad en https://www.youtube.com/watch?v=paERVK3BWII

${ }^{2}$ Por otra parte, se indica el documental "Periodico de Tela", celebrado en 2007, durante la inauguración del Museo de Salvador Allende, disponible en https://www.youtube.com/watch?v=aB7k4nudrKA
} 


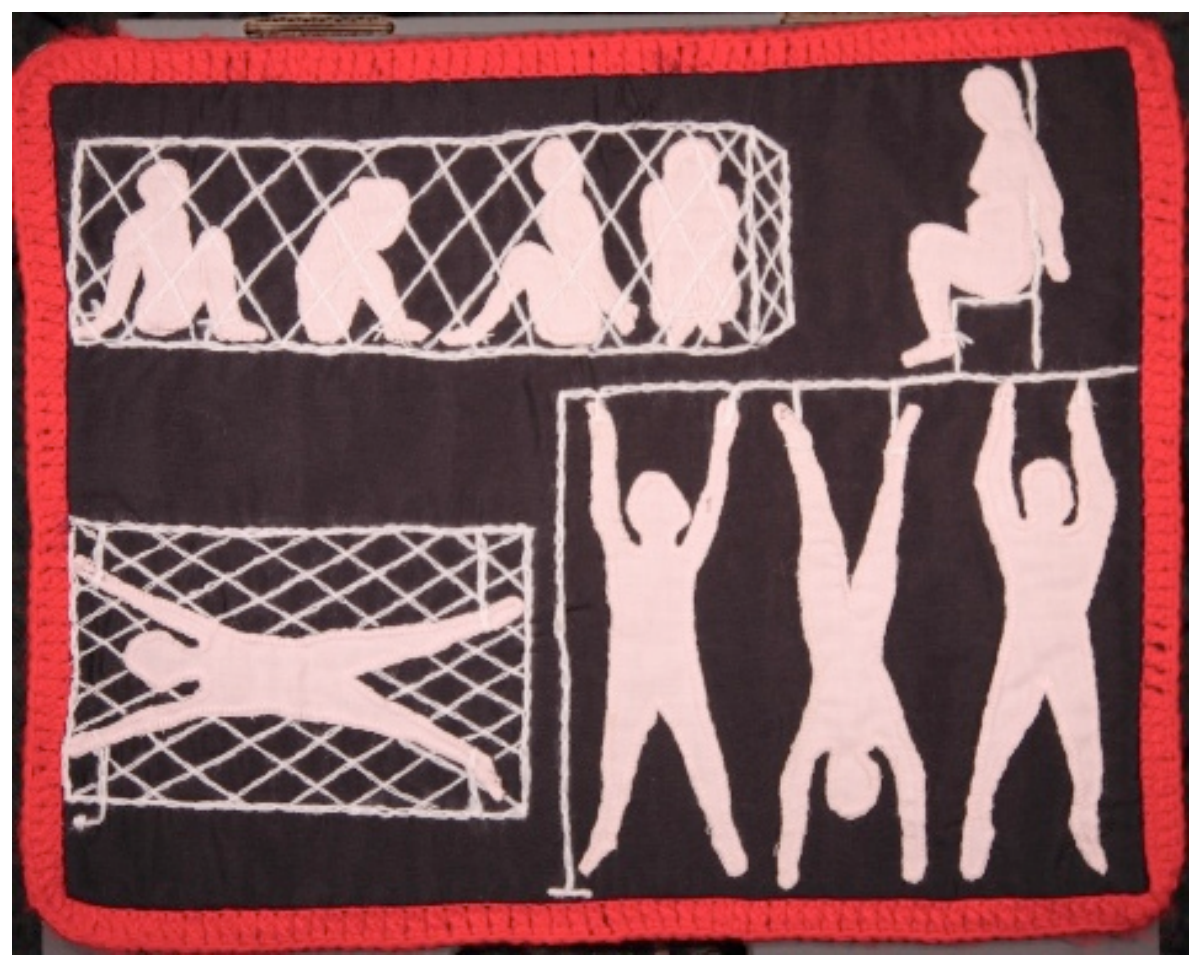

Ilustración 1. Arpillera de Chile.

Otro aspecto mencionado por Parker para la reanudación de interés por el trabajo manual y por todo lo que posee un aspecto natural, indica el escenario de recesión económica que fue diseñado en el centro de la primera década de este siglo. Aún en el esbozo de un escenario de crisis, Betsy Greer (en BUSZEK, 2014), que se atribuye - de acuerdo con la misma, erróneamente ${ }^{3}$ - la creación del término craftivismo, señala que a partir de septiembre de 2001 y los ataques que se llevaron a cabo en Nueva York, ha habido una atmósfera de frustración y rabia que proporcionó el ambiente en el que las manifestaciones pro y en contra de las muchas situaciones que se describían, por ejemplo, enviar o no tropas hacia el Oriente, se hizo posible, y por tanto el encuentro, la discusión, el choque y la posibilidad de repensar las formas para manifestarse.

De este modo surgen grupos que se reúnen a menudo con las reuniones programadas por Internet para aprender, enseñar y compartir las experiencias técnicas o de otro tipo - - y por lo tanto expresar sus opiniones sobre el contexto en el que se encuentran.

A menudo, antes de la formación del grupo y de las decisiones sobre el tipo de medidas que deben adoptarse (craftivista, activista, o no), existen discrepancias y cuestionamientos relativos a las condiciones observadas por los grupos. Sobre todo, se observa, el deseo de acción, de ganar voz y de marcar la posición. Ellos están proliferando abiertamente en las redes sociales, colectivos y clubes, donde más allá de conocer materiales y técnicas de manufactura de los diversos objetos, se propone discutir temas de la comunidad, como la ocupación del espacio urbano, que puede ser ejemplificado por el colectivo aguja cuya intervención en el Largo da Batata el 7 de junio, $2014^{4}$ "ilustra" la introducción de este artículo, levantando discusiones y tratando de compartir el conocimiento.

En tales acciones como las agenciadas por el colectivo aguja, se convoca el interesado, ya sea el tejedor / bordador, sea el transeúnte, que forme parte, y al desviar el uso común del objeto reconocible, se hace responsable del mundo que lo rodea.

Se establece un paralelo aquí con la propuesta por Hundertwasser (Ilustración 2), cuando formula sus pieles, en número cinco, siendo ellos la piel, ropa, hogar, social, la identidad y el medio ambiente global, que corresponde a la ecología y la humanidad. Hundertwasser, artista, arquitecto, ecologista y activista austríaco, propone un modelo conceptual en el que el hombre tiene sus pieles y que la acción de este hombre en cada una de las pieles tiene consecuencias sobre los demás. Por lo tanto, en este modelo de proposición, el sujeto de Hundertwasser es responsable de sí mismo y por todo lo que implica, en todos los niveles.

\footnotetext{
${ }^{3}$ Investigadora, artesana, activista y autor de "Craftivism: The Craft and Art of Activism". Vancouver: Arsenal Pulp Press, 2014, Betsy Greer señala que para el año 2000 el Colectivo Church of Craft había utilizado ese término y que Greer habría hecho popular. (En BUSZEK de 2011, p. 178).

${ }^{4}$ Para más información, ver el video en https://vimeo.com/98922028
} 


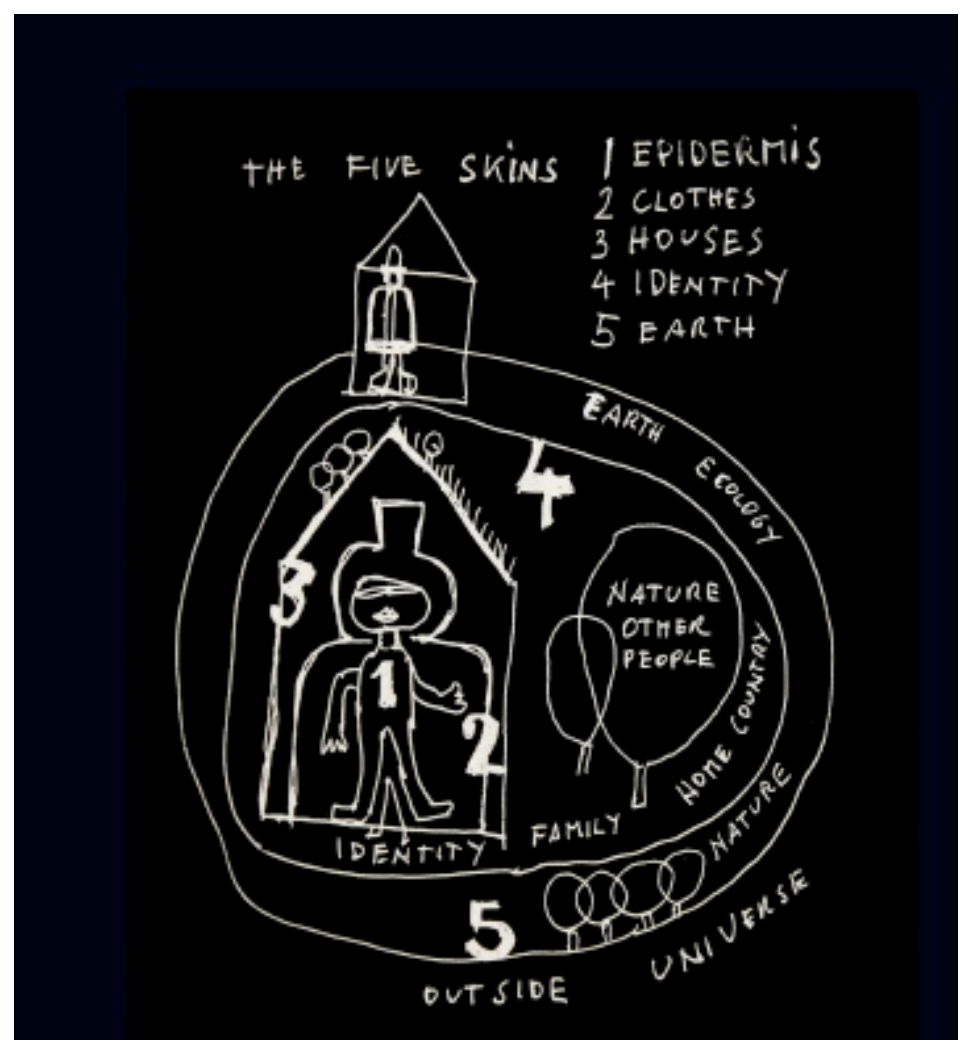

Ilustración 2. Propuesta visual de los Cinco Pieles de Hundertwasser Fuente: http://www.bioclimaticarquitetura.com.br/2009/07/hundertwasser-5-peles.html

Tomando los conceptos del austríaco como base para la comprensión de la producción craftivista, lo producido ya no puede fijarse a las tres primeras pieles: epidermis, ropa, hogar. En áreas como la moda, por ejemplo, la primera relación de la piel existente, la segunda piel y la cuarta piel se percibe como algo natural, es decir, la ropa es protectora del cuerpo, pero también hace la mediación simbólica con otras personas, lo que aumenta la aceptación de las relaciones y / o rechazo de los seres. Sin embargo, cuando se pone en ese mapa el craftivismo, el puente construido no atraviesa la tercera piel, se desborda del ámbito doméstico para el medio social del objeto - no sólo físico, sino también el tema de la discusión - y trae para el sujeto la responsabilidad por el territorio. Por lo tanto, se hace de la ciudad la extinción de la casa, marcando el territorio mediante el uso de objetos cuotidianos, en este caso, las toallitas, mantas, hechas lo más familiar posible.

Como si la bomba de hilos explotase dentro de su casa, el hombre lleva para el exterior elementos muy cuotidianos y los aloja en la ciudad, proponiendo el diálogo, pero también tomar posesión de ese espacio, lo que refuerza la idea de que el espacio público es público y no del poder público.

Sin embargo, con el fin de poner en práctica esa territorialización, gran parte de las acciones son hechas de forma colectiva. Es decir, incluso cuando hay un autor-proponente del "bombardeo", probablemente él tenía un número de colaboradores para producir la "bomba".

Como un bombardeo, el objetivo de yarnbombing es, antes de más nada disruptivo. Pero su efecto, lejos de ser destructivo, es propositivo, de modo que invita al público a participar en una conversación (Spampinato, 2015, p. 8), en la que se replanteen la utilización de la esfera pública.

A modo de ejemplo, se menciona la obra de la artista danesa Marianne Jorgensen, quien en 2006 cubrió un tanque de guerra M.24 Chaffee (Ilustración 3) en Aarhus, Dinamarca, con una manta hecha de fragmentos cuadrados de tejido de punto. 


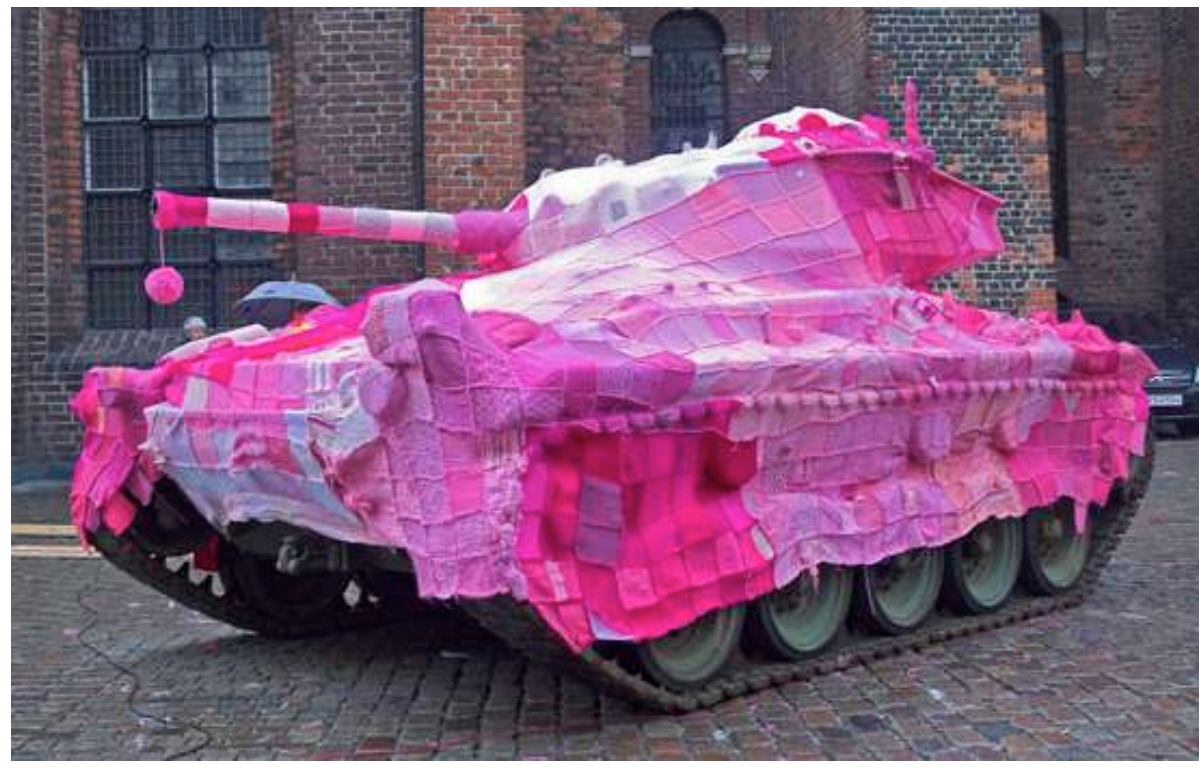

Ilustración 3. M24 Pink Chaffee Tank - Marianne Jorgensen - Aarhus, Dinamarca, 2006.

En esta acción se plantean una serie de cuestiones, incluyendo la participación de los sujetos en acción, la posición política clara, la ocupación inusual y el desvío del uso original del objeto producido para llamar la atención sobre el tema a tratar.

Así Jorgensen toma el uso habitual de las mujeres que se unieron para hacer mantas y edredones para el dote o para agazapar, acoger y abrigar a sus seres queridos, y pidió a varios grupos de trabajos de aguja expandidos por toda Europa para contribuir con el cuadrados tejidos en hilos de color rosado y que, como ella, también protestavan contra la ocupación de Irak por las fuerzas armadas extranjeras con el fin de manifestar su descontento con la participación de Dinamarca en el conflicto y el despliegue de tropas para aquel país. Además de las piezas tejidas, ella tenía un equipo de cuatro o cinco personas para unir los pedazos sobre la pieza de artillería y, también algunos transeúntes, interesados en la acción y la causa, se pusieron a ayudar a (Negro; Burisch, en BUSZEK 2011, p. 207-208).

En esta acción específica, el anonimato de los bombardeos se sustituye por yarnbombing colectiva. De acuerdo con Negro y Burisch (en BUSZEK, 2011), la manta hecha de piezas de ganchillo o de punto libre, en patrones determinados individualmente, era como una petición donde cada parte es la firma de un sujeto que rechaza la participación de su país (no sólo Dinamarca) en el conflicto antes mencionado. Esta petición, desviante, ocupa el espacio público y es imposible de ignorar, ya que la exhibición de un objeto habitual y acogedor que cubre un monumental artefacto y con un enorme potencial destructivo en lugar de ocultarlo, lo muestra por medio del absurdo de la acción.

Así con una bomba - de hilos - Jorgensen no borra el conflicto existente, pero toma el espacio público para mantenerlo presente, vivo, visible e incontrolable, dejando al mismo tiempo claro que su protesta no es aislada, y su descontento tiene eco y se manifiesta a través de la acción colectiva.

\section{Consideraciones finales.}

La construcción textil y la construcción del texto comparten una serie de términos, tales como líneas, entre líneas, hilo de la madeja, del tejido. A menudo, hay en la historia producciones de narrativas en el sector textil. Tejer o interferir con lo textil para narrar lo cuotidiano, aunque en un acto no raro, son acciones que se desvían del uso principal de lo que es textil en el caso de vestir, abrigar y todo tipo de empleo doméstico.

Sin embargo hay ejemplos en los que el desplazamiento de la utilidad proporciona otra experiencia más allá del uso diario. Se exploran técnicas y lenguajes para hacer referencia que escapan del día a día, a menudo porque esa misma idea - de día del día, de cuotidiano se encuentra rota. Por lo tanto, la inocencia y la práctica de los trabajos con agujas son utilizadas para resaltar cuestiones políticas, sociales y disidencias en casos en que estas partes vuelven a colocar y llegan al público para reportar quejas y tomar posiciones. A menudo, estas piezas a encuentran su voz en el espacio público y utilizan hasta el absurdo de su nueva dirección para dar fuerza a los discursos y promover el diálogo. 
Barbosa, Regina

Una Bomba Arrojada: reflexiones sobre razones y efectos de yarnbombing

III CONGRESO INTERNACIONAL DE INVESTIGACIÓN EN ARTES VISUALES :: ANIAV $2017::$ GLOCAL [codificar, mediar, transformar, vivir] http://dx.doi.org/10.4995/ANIAV.2017.4904

\section{FUENTES REFERENCIALES.}

AGOSín, Marjorie, 1987. Scraps of Life: Chillean Arpilleras. New Jersey: The Red Sea Press. ISBN 0-932415-28-8

BUSZEK, Maria Elena, 2011. Extra/Ordinary: craft and contemporary art. Durham: Duke Umiversity Press. ISBN 978-0-8223-4762-0

CARPENTER, Ele, 2010. Activist Tendencies in Craft. In: Concept Store \#3 Art, Activism and Recuperation. Arnolfini Journal, 3. Bristol. Disponible en hettp://eprints.gold.ac.uk/3109/

GOSTELOW, Mary, 1983. Embroidery: traditional designs, techniques and patterns all over the world. Nova lorque: Arco Publishing. ISBN 0-668-05910-9

MANN, Joanna, 2015 . Towards a politics of whimsy: yarn bombing the city. In: Area, 47.1, 65-72. Disponible en http://onlinelibrary.wiley.com/doi/10.1111/area.12164/abstract

PARKER, Rozsika, 2010. The Subversive Stitch, embroidery and the making of the feminine. Londres: I.B.Tauris. ISBN 978-1-84885-283-9

SPAMPINATO, Francesco, 2015. Come Together, the rise of cooperative art and design. Nova Iorque: Princeton Architectural Press. ISBN 978-1-61689-268-5

RESTANY, Pierre, 2008. Hundertwasser: o pintor-rei das cinco peles - Editora Taschen.ISBN 978-3-8228-0898-6 